\title{
An approach to diagnosing brain death in patients undergoing extracorporeal membrane oxygenation
}

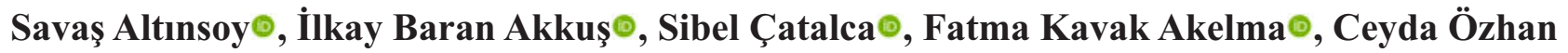 \\ Çaparlar๑, Jülide Ergilø
}

Department of Anesthesiology and Reanimation, University of Health Sciences, Dışkapı Yıldırım Beyazıt Training and Research Hospital, Ankara, Turkey

\section{ABSTRACT}

Objectives: This study was intended to discuss the process of brain death diagnosis of patients undergoing extracorporeal membrane oxygenation (ECMO) and our approach regarding the existing literature.

Methods: Demographics data (age, gender, admission diagnosis) were noted. ECMO type applied (venovenous or veno-arterial), time of diagnosing brain death (the time from admission time till diagnosis), being a donor or not, apnea testing application, supplementary tests applied at diagnosis stage (cerebral angiography, computerized tomography angiography, electroencephalography, transcranial doppler ultrasonography), and time of cardiac death (the time elapsing from the moment of brain death diagnosis till cardiac arrest) were noted.

Results: Forty-two patients data were exaimed and ECMO was applied to 8 patients, 4 of whom are female and the others are male. The average age of the patients is $61.8 \pm 9.8$ years. The average time elapsing from the hospitalization till brain death diagnosis was $2.5 \pm 0.5$ days. Apart from that, only $2(25 \%)$ of the patients were donors.

Conclusions: The use of modified apnea testing on patients undergoing ECMO could be proliferated if such tests are standardized and reliable guidelines are set. For this reason, we think that cerebral angiography should be kept in mind in addition to apnea test especially on ECMO-treated patients.

Keywords: Brain death, apnea test, extracorporeal membrane oxygenation, cerebral angiography

$\mathrm{B}$ rain death is a condition that involves the complete absence of voluntary movements, response to stimuli, consciousness, lower brain stem functions and spontaneous breathing accompanied by prolonged and permanent loss of all brain activity without reversible conditions. Apnea testing is a key component for diagnosing brain death. Apnea testing is regarded to yield a positive result if there is lack of spontaneous respiratory effort and increasing $\mathrm{PaCO} 2$ pressure above $60 \mathrm{mmHg}$ or an increase equal to or above 20
$\mathrm{mmHg}$ from the initial value [1]. Although apnea testing application is determined with a standard protocol, there are many modified tests which is used different methods in the literature. During apnea testing, many unwanted complications might occur, at varying levels, such as hypoxia, hypotension, barotrauma, pneumothorax, and cardiac arrest [2, 3]. For all these reasons, apnea testing should be performed after optimum conditions are met and the patient should be closely monitored. 
Extracorporeal membrane oxygenation (ECMO) is a procedure used to provide oxygenation in the case of cardiogenic shock and respiratory failure. It has two types as veno-venous and veno-arterial ECMO. Venovenous ECMO is often applied to patients who suffer from an acute respiratory failure such as refractory hypoxia (acute respiratory distress syndrome [ARDS], etc). On the other hand, veno-arterial ECMO is most suitable for sudden cardiac failure cases (after cardiac arrest, acute heart failure, post-cardiac surgery, etc). Nowadays ECMO is used with increasing frequency especially in medical centers where cardiac surgery is performed and, positive reports are shared about on its effectiveness [4]. Although it is not prevalent in the literature, there is no consensus on the protocol of apnea testing to be applied in patients who are undergoing resuscitative ECMO in intensive care units.

This study was intended to discuss the process of brain death diagnosis of patients undergoing ECMO and our approach regarding the existing literature.

\section{METHODS}

In the study, once consent was obtained from the local ethics committee (ref: 66/04, 28/06/2019), 42 patients data who were diagnosed with brain death from 2017 to 2019 were retrospectively reviewed. Eight of the patients, were included in the study as they were administered ECMO (Fig. 1). However, the patients for whom a written consent could not be obtained from their family and those who did not treat with ECMO were excluded from the study. A set of basic information was noted about the patients including demographics such as age and gender as well as admission diagnosis, ECMO type (venovenous or veno-arterial), time of diagnosing brain death (the time from admission time till diagnosis), being a donor or not, apnea testing application, supplementary tests applied at diagnosis stage (cerebral angiography, computerized tomographic angiography, electroencephalography, transcranial doppler ultrasonography), and time of cardiac death (the time elapsing from the moment of brain death diagnosis till cardiac arrest).

\section{RESULTS}

The patients' main data such as demographics (age and gender), admission diagnosis, type of ECMO, being a donor or non-donor, supplementary testings,

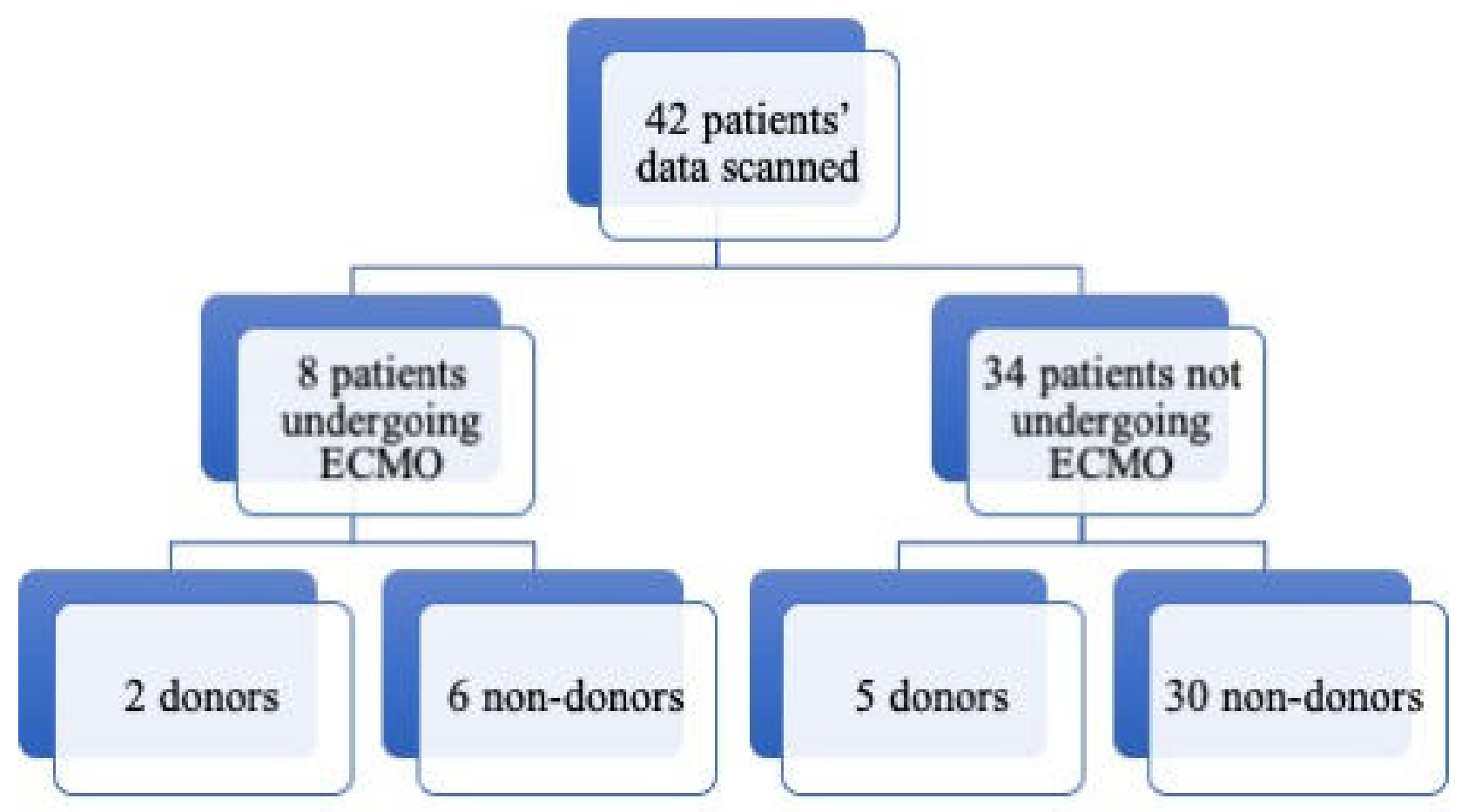

Fig. 1. Flow chart diagram about distribution of the cases. 
Table 1. Patients' characteristic data

\begin{tabular}{|c|c|c|c|c|c|c|c|c|}
\hline $\begin{array}{c}\text { Age } \\
\text { (years) }\end{array}$ & Gender & $\begin{array}{l}\text { Admission } \\
\text { diagnosis }\end{array}$ & $\begin{array}{c}\text { ECMO } \\
\text { indication }\end{array}$ & $\begin{array}{l}\text { ECMO } \\
\text { type }\end{array}$ & $\begin{array}{c}\text { BD } \\
\text { diagnosis } \\
\text { time (days) }\end{array}$ & $\begin{array}{c}\text { Supplementary } \\
\text { testings }\end{array}$ & $\begin{array}{l}\text { Time of } \\
\text { arrest } \\
\text { (days) }\end{array}$ & Donor \\
\hline 67 & Female & Dissection & $\begin{array}{l}\text { Cardiovascular } \\
\text { failure }\end{array}$ & $\mathrm{V}-\mathrm{A}$ & 3 & $\mathrm{EEG}, \mathrm{CA}$ & 2 & No \\
\hline 58 & Female & CHD & $\begin{array}{l}\text { Cardiovascular } \\
\text { failure }\end{array}$ & $\mathrm{V}-\mathrm{A}$ & 2 & $\mathrm{EEG}, \mathrm{CA}$ & 1 & No \\
\hline 42 & Male & Cardiac trauma & $\begin{array}{l}\text { Cardiovascular } \\
\text { failure }\end{array}$ & $\mathrm{V}-\mathrm{A}$ & 3 & $\mathrm{CA}$ & 1 & Yes \\
\hline 69 & Male & Dissection & $\begin{array}{l}\text { Cardiovascular } \\
\text { failure }\end{array}$ & $\mathrm{V}-\mathrm{A}$ & 2 & $\mathrm{CA}$ & 1 & No \\
\hline 74 & Male & Aorta Aneurysm & $\begin{array}{l}\text { Cardiovascular } \\
\text { failure }\end{array}$ & $\mathrm{V}-\mathrm{A}$ & 2 & $\mathrm{EEG}, \mathrm{CA}$ & 2 & No \\
\hline 67 & Female & $\begin{array}{l}\text { Mitral and aortic } \\
\text { valve } \\
\text { replacement }\end{array}$ & $\begin{array}{l}\text { Cardiovascular } \\
\text { failure }\end{array}$ & $\mathrm{V}-\mathrm{A}$ & 3 & $\mathrm{CA}$ & 1 & No \\
\hline 58 & Female & Dissection & $\begin{array}{l}\text { Cardiovascular } \\
\text { failure }\end{array}$ & V-A & 2 & $\mathrm{CA}$ & 1 & Yes \\
\hline 60 & Male & Acute MI & $\begin{array}{c}\text { Cardiovascular } \\
\text { failure }\end{array}$ & V-A & 3 & $\mathrm{EEG}, \mathrm{CA}$ & 2 & No \\
\hline
\end{tabular}

$\mathrm{ECMO}=$ Extracorporeal membrane oxygenation, $\mathrm{BD}=$ Brain death, $\mathrm{CHD}=$ Coronary heart disease, $\mathrm{MI}=\mathrm{Myocard}$ infarctus, $\mathrm{V}-\mathrm{A}=$ Veno-arterial, $\mathrm{EEG}=$ Electroencephalogram, $\mathrm{CA}=$ Cerebral angiography

and time of cardiac arrest are given in Table 1. ECMO was applied to 8 patients, 4 of whom are female and the others are male. The average age of this patients is $61.8 \pm 9.8$ years. In addition, V-A ECMO was applied to all this patients because of cardiovascular failure after cardiac surgery. With regards to diagnostic supplementary tests, four of the patients underwent electroencephalography as well as cerebral angiography, and the other four underwent only cerebral angiography. The average time from admission to the diagnosis of brain death was $2.5 \pm$ 0.5 days. Only $2(25 \%)$ of this eight patients were donors.

\section{DISCUSSION}

The process of brain death diagnosis is important due to several reasons. In a study in Europe suggested that $2-3 \%$ of all patients dying in a hospital and $14 \%$ of those dying in intensive care units result in brain death [5]. Firstly, the diagnosis should be completed in the most appropriate time and as soon as possible. All kinds of delays that may occur during the diagnosis and the decision stage affect organ donation adversely. Diagnosis of brain death in some specific cases is known to be difficult and time-consuming. Particular caution is required in cases where the gas exchange is carried out externally and stopping or interrupting the Exchange endangers the patient's life (ECMO, carbon dioxide absorbers, etc.). ECMO is an advanced technique which is often applied as the last chance in cardiac and respiratory failure. However, many neurological complications, especially brain death, occur during the performance of it. The diagnosis of brain death does not come into mind so fast in ECMO patients. Therefore, in such cases, the main goal of the diagnosis should be to shorten the time and keep the patient more stable. One component of brain death diagnosis, apnea testing, is an indispensable part of the diagnostic process. Despite its crucial value, apnea testing can cause many complications including cardiac arrest $[2,3]$. Besides, the diagnosis of brain death by apnea testing in ECMO patients involves a difficult and complex process. Especially in veno-arterial ECMO, application and interpretation of the apnea testing become even more difficult due to both gas exchange and circulatory support [6]. Since there is no valid guideline published on this subject, practices are limited to clinical 
experience. For all these reasons, apnea testing was not administered no patients who was treated with ECMO in this study.

Apnea testing is a recommended and obligatory test at the diagnosis stage of brain death. Although modified methods have recently been used to prevent complications related to apnea testing, those testings that was applied especially in ECMO patients are mostly at the level of case presentation [7]. So far, apnea testing has been tried by adding exogenous $\mathrm{CO}_{2}$ to ECMO [8], monitoring the respiratory effort by applying continuous positive pressure [9], and reducing the sweep gas flow $[10,11]$; nonetheless, no successful apnea test has been found in all cases presented. For example, Giani et al. [12] found that the rate of severe hypoxia during modified apnea testing was $8 \%$ in the ECMO-treated group, it was $2.4 \%$ in the control group. Furthermore, those in the ECMO group required higher $\mathrm{FiO}_{2}$, higher PEEP, higher tidal volume, and higher airway pressures than patients in the non-ECMO group. In a study where modified apnea testing was applied successfully; the patient was taking triple inotrope and although the apnea testing was completed, hemodynamic changes or arrhythmias were not noted during or after the testing [10]. Like the apnea testing, reliability of biomarkers such as BIS, transcranial Doppler, or glial fibrillary acidic protein (GFAP) was not fully established [13-15]. Absence of cerebral circulation is important for the diagnosis of brain death. Cerebral angiography is a procedure that directly demonstrates the absence of cerebral blood flow. Duly performed cerebral angiography and carotid bifurcation or absence of flow above the Willis polygon is particularly important for the diagnosis [16]. In the current study, all patients with treated ECMO were had unstable hemodynamic values and treated with vasoactive medications. Considering all these reasons; cerebral angiography, which is the gold standard in the diagnosis of brain death, was performed in patients who underwent ECMO. No complications were observed during the procedure.

Brain death is a clinical diagnosis, yet the diagnosis criteria vary from one country to another. In a study, it was pointed out that supplementary testing is imposed as a prerequisite for the diagnosis of brain death in $40 \%$ of all countries [17]. However, no study has been published on supplementary tests for patients going through ECMO, only with findings at a certain extent. Bronchard et al. [18], apnea testing was not performed on $62.5 \%$ of donors who went through ECMO before diagnosing brain death. In that study, 24 patients were subjected to apnea testing but the testing could not be finished with 10 of them. As for the supplementary testings' in brain death, $53 \%$ of the ECMO-treated patients went under computerized tomographic angiography and 39\% experienced electroencephalography. By contrast, in the group which was not applied ECMO, it apnea testing was noted to be performed successfully by $71.9 \%$ [12]. In the present study, all of the subjects undergoing ECMO and diagnosed with brain death are patients who were hemodynamically unstable following cardiac surgery performed with veno-arterial ECMO. None of the patients were treated with apnea testing, without prejudice to cerebral angiography on all. The reason could be the motivation to prevent complications (hypoxia, arrhythmia, etc) in ECMOtreated patients with unstable hemodynamics as a result of apnea testing and, more importantly, the lack of a valid set of guidelines published on this matter.

In patients undergoing extracorporeal membrane oxygenation, concerns about the chance of being donors are at least as important as brain death diagnosis. In an example study investigating brain death in ECMO-treated patients in relation with eligibility for being donors, 10,869 of total 22,270 patients donated at least one organ, leading to being donors in ECMO-treated and the control group by $39.8 \%$ and $48.9 \%$, respectively $(p=0.02)$ [18]. Additionally, it was reported that the transplantation team demanded organs from ECMO-treated patients less frequently. However, no difference was found between the groups after one year's follow-up in terms of renal graft survival and functions. It was added that ECMO-treated patients who were diagnosed with brain death can also make good donors [18]. In another study, Fan et al. [19] regarded ECMO as a step for preserving organs of patients diagnosed with brain death; consequently, they reported improved results on liver and kidney transplantation (an increase from $47.8 \%$ to $84.6 \%$ ). Moreover, in case presentations by Lee et al. [20].

ECMO was performed on 3 patients diagnosed with brain death and 11 organs from these patients were transplanted on 10 patients successfully. 
However, ethical issues might arise in connection with patients for whom organ donation consent could not be finished and who are currently under ECMO during brain death. In our study, only 2 (25\%) of the ECMOtreated patients became donors. This figure corresponds to a lower level than the overall literature, which might be accounted for by cultural and religious beliefs among different nations as well as other attitudes.

\section{CONCLUSION}

As a conclusion, although several modified apnea testings were applied for brain death during ECMO, cerebral angiography remains a definite method in this regard. The use of modified apnea testing on patients undergoing ECMO could be proliferated if such tests are standardized and reliable guidelines are set. For this reason, we think that in addition to apnea test, cerebral angiography should be kept in mind, especially on ECMO-treated patients with unstable hemodynamics variable.

\section{Authorship declaration}

All authors listed meet the authorship criteria according to the latest guidelines of the International Committee of Medical Journal Editors, and all authors are in agreement with the manuscript.

\section{Author contributions}

SA, İBA, SÇ = conception and design; SA, SÇ, FKA, CÖÇ = data collection; FKA, CÖÇ = analysis and interpretation; SÇ, SA, İBA, JE = literature review and writer, and $\mathrm{JE}=$ critical review.

\section{Conflict of interest}

The authors disclosed no conflict of interest during the preparation or publication of this manuscript.

\section{Financing}

The authors disclosed that they did not receive any grant during conduction or writing of this study.

\section{REFERENCES}

1. Practice parameters for determining brain death in adults (summary statement). The Quality Standards Subcommittee of the American Academy of Neurology. Neurology 1995;45:10124.

2. Thery G, Rosman J, Julien G, Chaix F, Mateu P. Brain death: bilateral pneumothorax and pneumoperitoneum after an apnoea test. Anaesth Crit Care Pain Med 2019;38:89-90.

3. Sołek-Pastuszka J, Sawicki M, Iwańczuk W, Kojder K, Saucha $\mathrm{W}$, Czajkowski Z, et al. Apnea testing using the oxygen insufflation method for diagnosis of brain death may compromise pulmonary function. J Crit Care 2018;44:175-8.

4. Xie A, Lo P, Yan TD, Forrest P. Neurologic complications of extracorporeal membrane oxygenation: a review. J Cardiothorac Vasc Anesth 2017;31:1836-46.

5. Giuseppe Citerio, MD, Paul G. Murphy, MD. Brain death: the European perspective. Semin Neurol 2015;35:139-44.

6. Saucha W, Solek-Pastuszka J, Bohatyrewicz R, Knapik P. Apnea test in the determination of brain death in patients treated with extracorporeal membrane oxygenation (ECMO). Anaesthesiol Intensive Ther 2015;47:368-71.

7. Smilevitch P, Lonjaret L, Fourcade O, Geeraerts T. Apnea test for brain death determination in a patient on extracorporeal membrane oxygenation. Neurocrit Care 2013;19:215-7.

8. Pirat A, Komurcu O, Yener G, Arslan G. Apnea testing for diagnosing brain death during extracorporeal membrane oxygenation. J Cardiothorac Vasc Anesth 2014;28:e8-9.

9. Muralidharan R, Mateen FJ, Shinohara RT, Schears GJ, Wijdicks EF. The challenges with brain death determination in adult patients on extracorporeal membrane oxygenation. Neurocrit Care 2011;14:423-6.

10. Hoskote SS, Fugate JE, Wijdicks EF. Performance of an apnea test for brain death determination in a patient receiving venoarterial extracorporeal membrane oxygenation. J Cardiothorac Vasc Anesth 2014;28:1027-9.

11. Smilevitch P, Lonjaret L, Fourcade O, Geeraerts T. Apnea test for brain death determination in a patient on extracorporeal membrane oxygenation. Neurocrit Care 2013;19:215-7.

12. Giani M, Scaravilli V, Colombo SM, Confalonieri A, Leo R, Maggioni E, et al. Apnea test during brain death assessment in mechanically ventilated and ECMO patients. Intens Care Med 2016;42:72-81.

13. Jouffroy R, Lamhaut L, Guyard A, Philippe AK, Spaulding $\mathrm{C}$, Baud F, et al. Early detection of brain death using the Bispectral Index (BIS) in patients treated by extracorporeal cardiopulmonary resuscitation (E-CPR) for refractory cardiac arrest. Resuscitation 2017;120:8-13.

14. Bembea MM, Savage W, Strouse JJ, Schwartz JM, Graham E, Thompson CB, et al. Glial fibrillary acidic protein as a brain injury biomarker in children undergoing extracorporeal membrane oxygenation. Pediatr Crit Care Med 2011;12:572-9.

15. Kavi T, Esch M, Rinsky B, Rosengart A, Lahiri S, Lyden PD. Transcranial doppler changes in patients treated with extracorporeal membrane oxygenation. J Stroke Cerebrovasc Dis 2016;25:2882-5.

16. Spinello IM. Brain death determination. J Intensive Care Med. 2015;30:326-37.

17. Wijdicks EF. Brain death worldwide: accepted fact but no global consensus in diagnostic criteria. Neurology 2002;58:20- 
5.

18. Bronchard R, Durand L, Legeai C, Cohen J, Guerrini P, Bastien O. Brain-dead donors on extracorporeal membrane oxygenation. Crit Care Med 2017;45:1734-41.

19. Fan X, Chen Z, Nasralla D, Zeng X, Yang J, Ye S, et al. The organ preservation and enhancement of donation success ratio effect of extracorporeal membrane oxygenation in circulatory unstable brain death donor. Clin Transplant 2016;30:1306-13. 20. Lee H, Cho YH, Sung K, Yang JH, Chung CR, Jeon K, et al. The use of extracorporeal circulation in suspected brain dead organ donors with cardiopulmonary collapse. J Korean Med Sci 2015;30:1911-4. 